\title{
Review of Siân Bayne, Peter Evans, Rory Ewins, Jeremy Knox, James Lamb, Hamish Macleod, Clara O'Shea, Jen Ross, Philippa Sheail, and Christine Sinclair (2020). The Manifesto for Teaching Online
}

\section{Cambridge, MA: MIT Press. 272 pp. ISBN 9780262539838 (Paperback)}

\section{Lesley Gourlay ${ }^{1}$}

Published online: 12 January 2021

(C) Springer Nature Switzerland AG 2021

Keywords Manifesto $\cdot$ Teaching online $\cdot$ Digital education $\cdot$ Sociomaterialism .

Posthumanism $\cdot$ Big data $\cdot$ Algorithm $\cdot$ Analytics $\cdot$ MOOC $\cdot$ Surveillance $\cdot$ Edinburgh

\section{Introduction}

The first page of this multi-authored book immediately grabs the attention in terms of its appearance. It consists of a series of statements (and one question), set out one-byone. The first three statements are:

Online can be the privileged mode. Distance is a positive principle, not a deficit.

Place is differently, not less, important online. Text has been troubled: many modes matter in representing academic knowledge. (Bayne et al. 2020: xi)

This textual arrangement, I felt, signals to the reader that the rhetorical intent of the book is somewhat unusual for an academic publication, an impression which is intensified by the illustrations throughout the book. The explicit positioning of the piece in a different genre from conventional academic text is a thought-provoking, from a group of researchers who have consistently questioned assumptions surrounding what constitutes 'legitimate' or effective academic expression. They quote Latour:

Lesley Gourlay

1.gourlay@ucl.ac.uk

1 University College London Institute of Education, London, UK 
[A manifesto makes] explicit (that is, manifest) a subtle but radical transformation in the definition of what it means to progress, that is, to process forward and meet new prospects. Not as a war cry for an avant-garde to move even further and faster ahead, but rather as a warning, a call to attention, so as to stop going further in the same way as before toward the future. (Latour 2010: 473 in Bayne et al. 2020: xiii)

The phrase which resonates for me in this definition is 'a call to attention', which suggests a subtle, ethnographic sensibility, rather than the somewhat strident overtones that the word 'manifesto' may carry for some. This book is the third iteration of 'The Manifesto for Teaching Online' which was first developed by this Edinburgh University team in 2011. This is an academic group which has come to prominence in the field of postdigital education through their innovative work around MOOCs, their groundbreaking MSc programme in Digital Education and an associated set of research projects and publications. The authors viewed the purpose of the manifesto as to critique two tendencies they saw in higher education: '(1) the impoverished technocorporate futures for education being normalized by corporate and government 'ed-tech' and (2) the orthodoxies framing traditional higher education teaching, which so often fail to properly account for digital methods.' (xvii) These are both vital critical projects, and this group of researchers has been interrogating the assumptions underlying these for some time, via their research and commentary. What is of interest here, I would suggest, is that their critique both challenges overblown and clichéd discourses surrounding online education, but also seeks to value it in a manner which is nuanced, open-ended and creative.

In this spirit of challenging supposedly 'commonsense' notions about higher education, they set out that the focus is 'unapologetically about the practice and profession of teaching in higher education' (xxii). I found this clear rejection of the orthodoxy of 'learnification' and erasure of the teacher (Biesta 2012, 2017) refreshing; this sets a very strong opening critical tone. The manifesto arises from the authors' strongly intertwined approach to teaching and research, drawing on their MSc programme, which has consistently innovated and troubled the assumed boundaries of what constitutes online teaching for some years. Full disclosure: I am their external examiner and so very familiar with the course.

\section{Beyond the Social}

The book is organised into five sections, which arrange points from the 2016 version of the manifesto into clusters, around a series of themes. Section I focuses on 'politics and instrumental logics' (1), setting out their theoretical stall from the outset. A central element of this is the recognition of online teaching as emergent and sociomaterial, which is set in contrast to notions of context-free 'best practice'. Adopting a posthuman perspective, materiality and the agency of objects is emphasised here and throughout. They include 'snapshots', which provide examples of practice, in this case discussing their use of Second Life and subsequently Minecraft on the MSc as playful, contingent and emergent spaces for teaching. They remind us that 'the social isn't the whole story' (13). The persistent fantasies in the sector of free-floating subjectivities-somehow 
untrammelled by material or temporal constraints - are called into question, drawing on a rich theoretical base which moves us away from preoccupations with human agency. For readers new to this sociomaterial perspective, this offers a very clear and persuasive overview, and as a result is likely to bring this vital point to a wider audience in the sector. The argument is made that 'online teaching need not be complicit with the instrumentalism of education' (17). A closely argued and rigorous interrogation of the assumptions behind the 'knowledge economy' is presented, also questioning the view that education is primarily for the development of economic success and enhancement of 'human capital'. The authors point out the threat this represents to the critical function of higher education, and argue that the digital in higher education is particularly associated with instrumentalism, such as in discourses focusing on 'technological skills' required for the workplace.

The role of digital technology in the corporatisation of the university is also drawn out, with examples given of standardised technological 'top-down' technological systems for teaching, and the threat they may pose to the autonomy of academics. The assumption that teaching online leads to cost savings contributes to this, and technologies are also seen as being at the centre of processes of 'unbundling', allowing for-profit players to enter. However, the authors argue that this is not an inevitability, and propose that teaching online can defy these logics, via practices and approaches which inculcate 'uncertainty, risk and complexity' (23). I found this section to be particularly resonant, alongside the follow-up point that 'online teaching should not be downgraded to facilitation' (25), all of which feels particularly apposite in our current context of a mass shift to online teaching, due to the Covid-19 crisis. This section concludes with an incisive critique of the persistent term 'digital natives'.

\section{Beyond Words?}

The book is wide-ranging and progresses in an equally critical and highly thoughtprovoking manner through 4 further sections. Section II, 'Beyond words' (41), is a fascinating consideration of the relationships between digital technologies and academic writing, in a 'post-text' digital setting characterised by possibilities for 'shared authorship, collaboration, and digital re-mix' (45-46). The potentially profound effects on the nature of authorship and assessment are considered, with a discussion of multimodality and the potentials of semiotic resources beyond linguistic text, in terms of representation in digital higher education. The authors describe in the 'snapshot' the wide range of creative ways in which students on the course have expressed their ideas in different multimodal genres:

Other students have embedded self-designed games in essays on game-based learning; developed essays entirely in game form; recorded Google Streetview flyovers to describe mobile learning; created open educational resources to open up their ideas for global re-use; overlaid their scholarship onto video and poetry; created images composites, written songs, and written code; and created rabbit holes of interlinked digital text. (Bayne et al. 2020: 52-53) 
The authors argue that this is not 'digital play for its own sake', but instead is an exercise in extending meaning, by using a range of media. This approach has clearly been highly generative in the context of the course. However, I did wonder about how applicable these approaches might be to other types of learning outcomes, in disciplines which are not concerned with digital practice as an object of analysis and discussion. The possible limitations of applying this approach in high-stakes assessment situations which are normally dominated by an essayist tradition are acknowledged. The authors go on to discuss the constitutive nature of interface design on learning, in particular the aesthetic and design aspects of pedagogy when using a learning management system. I felt this important point could have been developed a bit further, by perhaps addressing how university educators might go about personalisation, in settings where the Learning Management System is presented in a standardised format.

The next section focuses on the nature of authorship in digital environments, arguing that elements from digital sources such as YouTube videos can be juxtaposed with other elements such as hyperlinks, in order to work with multiple genres in a form of 'cut and paste'. Again, the potential limitations of this approach are discussed, in terms of citation and authorial responsibility. The argument moves on to a consideration of how multimodal representation might change academic assessment and the challenges inherent in this approach are discussed in terms of identifying and assessing the student's own authorial voice. The concluding statement is that 'assessment is an act of interpretation, not just measurement' (67). However, I would venture to argue that this is also the case in 'traditional' assessment of written work. This section overall felt less sure-footed than the rest of the book, although it does provide the reader with some provocative ideas about the nature of academic argument and expression, concluding with a creative consideration of how digital assignments might 'live on' across networked platforms in the public domain, and continue to be edited or added to beyond the point of assessment.

\section{Recoding, Algorithms and Analytics}

The next section consists of a discussion of 'Re-coding Education' (77), by taking a critical look at 'open education', MOOCs, the role of algorithms in higher education, and the implications of increased automation. This sustained critique of the hyperbole that tends to surround these technologies is welcome, with a highly nuanced and insightful discussion of what is meant by the term 'open' drawing on Knox's (2013) application of Isaiah Berlin's (1969) concept of negative and positive liberty, in which Knox argues that openness is commonly associated with negative liberty in digital education and the removal of obstacles, as opposed to positive liberty. The tendency of MOOCs and the Open Education Resources movement to reinscribe neoliberal 'client' subjectivities is explored, alongside various other complexities associated with this field of practice. I found this one of the strongest and most worked-through sections of the book, in terms of both theory and the consequences of the critique. However, being longer and more detailed than some of the other sections, it also slightly gave the impression of belonging to another book, perhaps an inevitable consequence of having so many authors involved.

The following section focused on the exhortation 'Algorithms and analytics re-code education: pay attention!' (103). The concept of 'recoding' of education through online teaching and specifically learning analytics is advanced, rather than relying on assumptions 
surrounding 'augmentation' or 'enhancement'. The repercussions for the role of the teacher are explored, in particular the ways in which the teacher is sidelined by the technology, and rendered as a problem to be solved. The 'blackboxed' (Latour 1999) nature of the technology conceals the 'workings' and leads to a focus on outputs. A very thorough discussion follows, exploring algorithmic decision-making, bias, and the resultant production of educational realities, as opposed to mere measurement. The final point in this section turns to the question of automation, with the statement 'we welcome our new robot colleagues' (111).

I confess that this jarred for me a little. The authors recognise the apparent incongruity of this stance in relation to the preceding critiques, but make a case of the potential value of interventions which might remove burdensome tasks such as marking. The angle taken here is that to reject automation is to reinscribe humanism. I was only partially convinced by this - it is undeniable that education is already (and always has been) intertwined with technologies and nonhuman actors. However, for me that did not represent a compelling enough argument to support the position being advocated regarding a (cautious) welcoming of automation, which sat oddly with the preceding section, although the concluding point about teachers having agency over automation was a good one. The 'snapshot' provides the example of the 'teacherbot', which interacted with students on the 'E-learning and Digital Cultures MOOC' via Twitter (118), as described in Bayne (2015). The bot was designed in such a way as to surface and draw attention to the interface between the human and automated in education, and in that sense, it was clearly a highly effective heuristic. However, rather like the multimodal forms of online assessment described earlier in the book, I find it hard to see how this approach might be used outside of the context of a course which is focused on digital education. I fear that in these two instances, the team may have fallen down the same rabbit hole as many 'ed tech' enthusiasts before them. But then, their role is to test and worry at these boundaries and assumptions, which they do to great effect here.

\section{Face, Place and Surveillance}

By this point, the reader has been taken through a fascinating journey of critique and questioning, and if I'm honest, I felt like I needed a breather (although that also might have been related to my lockdown insomnia). The sheer breadth of the scope can feel a bit dispersed. It's a rich brew, and at time the book gives the impression to those of us familiar with the work of this group of a round-up of their 'greatest hits'. Nevertheless, I pushed on to the next section, 'Face, place and space' (125), and was rewarded with an excellent examination of these related concepts, which I found strikingly relevant to our current Covid-19 predicament. Although I fundamentally disagree with the contention that 'face time is overvalued' (141), the argument is well-made here that the online environment can provide both contact and serendipity, often assumed to be the sole preserve of the face-toface. They apply mobilities theory (e.g. Urry 2007) to generate a rich disquisition of the nature of place in the context of online education, and propose a recasting of 'commonsense' concepts such as 'distance', recasting it as not only spatial in its nature, but also temporal, affective, and political. I feel I could delve further into this area but space prohibits it herethis section should be required reading (and thinking) in my view for all decision-makers at universities currently engaged in the challenges of moving to online teaching. 
The final section of the book focuses on 'Surveillance and mistrust' (165), which I was a little surprised to see separate from the section on algorithms. Drawing on Lyon's construct of surveillance culture (2017), the authors contend that 'visibility is a pedagogical and ethical issue' (167). A rich critical discussion ensues, regarding the nature of surveillance, its effects and the ethical implications. Astutely, they link this critique to the work of Macfarlane (2013, 2016) on monitoring of student behaviour on campus, and his construct of 'bodily performativity'. Plagiarism detection software is given as an example of a technology which engenders mistrust, and damages the pedagogic relationship. I am writing this review after reading a news story about students at a UK university tearing down fences erected around their halls of residence. These were, as I understand it, designed to funnel the students through one gate, which could only be entered with an electronic card. This underlines the point that a robust and urgent critique of the ethical risks around these burgeoning surveillance cultures is absolutely vital at this time, and this excellent chapter is a bracing reminder of what is at stake.

In conclusion, I expect that this book will be deservedly regarded as an absolutely seminal contribution to the critical literature on digital education for many years to come. Its scope, erudition, and sheer audacity of thought demand that the reader sit up and examine her assumptions and those of the field in new, and sometimes dizzying ways. It is clearly an ensemble piece, and there are one or two places they do not seem to sing the same song. But that, I would expect, would be regarded by the team as a reflection of the messy, restless and emergent nature of the field, of criticality, and of knowledge itself. I'll take the liberty of adding one more element to their manifesto. Read this book.

\section{References}

Bayne, S. (2015). Teacherbot: interventions in automated teaching. Teaching in Higher Education, 20(4), 455-467. https://doi.org/10.1080/13562517.2015.1020783.

Bayne, S., Evans, P., Ewins, R., Knox, J., Lamb, J., Mcleod, H., et al. (2020). The Manifesto for Teaching Online. Cambridge, MA: MIT Press.

Berlin, I. (1969). Two concepts of liberty. In I. Berlin (Ed.), Four essays on liberty (pp. 155-165). London: Oxford University Press.

Biesta, G. (2012). Giving teaching back to education: responding to the disappearance of the teacher. Phenomenology \& Practice, 6(2), 35-49. https://doi.org/10.29173/pandpr19860.

Biesta, G. (2017). The rediscovery of teaching. Abingdon: Routledge.

Knox, J. (2013). Five critiques of the open educational resources movement. Teaching in Higher Education, 18(8), 821-832. https://doi.org/10.1080/13562517.2013.774354.

Latour, B. (1999). Pandora's hope: essays on the reality of science studies. Cambridge, MA: Harvard University Press.

Latour, B. (2010). An attempt at a 'compositionist manifesto'. New Literary History, 41(3), 471-490.

Lyon, D. (2017). Surveillance culture: engagement, exposure, and ethics in digital modernity. International Journal of Communication, 11, 824-842.

Macfarlane, B. (2013). The surveillance of learning: a critical analysis of university attendance policies. Higher Education Quarterly, 67(4), 358-373. https://doi.org/10.1111/hequ.12016.

Macfarlane, B. (2016). Freedom to learn. Abingdon: Routledge.

Urry, J. (2007). Mobilities. Cambridge, UK: Polity Press. 